\title{
The Role of Organizational Commitment in Occupational Stress Models
}

\author{
Sharon Glazer \\ San José State University \\ Bradford Kruse \\ Qwest Communications, Inc., Denver, Colorado
}

This study examined affective organizational commitment (AOC) and continuance organizational commitment (COC) as moderators of the relationship between job-related anxiety and intention to leave among 506 Israeli nurses who completed self-administered surveys. Prior research examining organizational commitment as a moderator between stress-related variables has shown inconsistent results, most probably because organizational commitment was tested as a moderator of stressor-strain relationships. Both $A O C$ and $C O C$ buffered the relationship between job-related anxiety and intention to leave the hospital (i.e., the positive relationship was not as strong with high levels of commitment). There was no buffering effect on the relationship between role stressors and intention to leave. Further, the relationship between job-related anxiety and intention to leave increased more strongly for low levels (vs. high levels) of COC. Implications for the role of organizational commitment in stress models and implications for hospital administrators are discussed.

Keywords: organizational commitment, occupational stress, anxiety, intention to leave

Organizational commitment, which is the subjective attachment one has with his or her employing organization, is a global and stable variable (Mowday, Porter, \& Steers, 1982) that provides meaning to work situations (Leong, Furnham, \& Cooper, 1996). Lack of organizational commitment has

Sharon Glazer, Department of Psychology, San José State University; Bradford Kruse, Qwest Communications, Inc., Denver, Colorado.

The authors appreciate the help of Dr. Nora Reilly and Dr. Terry A. Beehr for their thoughtful reviews and critiques of this paper.

Correspondence concerning this article should be addressed to Sharon Glazer, Department of Psychology, San José State University, 1 Washington Square, San José, CA 95192-0120. E-mail: sharon.glazer@sjsu.edu

International Journal of Stress Management 
been studied (a) as a psychological outcome of organizational situations (e.g., Leiter, 1988; O'Driscoll, Ilgen, \& Hildreth, 1992), including stressors; (b), as a predictor of intention to leave (e.g., Meyer, Stanley, Herscovitch, \& Topolnytsky, 2002); and (c) as a mediator of the relationship between role stressors and withdrawal behaviors (Bakker, Demerouti, de Boer, \& Schaufeli, 2003; Glazer \& Beehr, 2005). Recent studies have also examined organizational commitment as a moderator of stressor-strain relationships (Leong et al., 1996; Reilly, 1994; Reilly, Dwight, Godfrey, Davis, \& Lynch, 1994; Siu \& Cooper, 1998) and a moderator (Begley \& Czajka, 1993; Jamal, 1984) or mediator (Glazer \& Beehr, 2005) of the relationship between two strain variables. However, results on the moderating role of organizational commitment in stress research remain inconclusive.

In several studies (e.g., Donald \& Siu, 2001; Leong et al., 1996; Reilly, 1994; Reilly et al., 1994; Siu, 2002; Siu \& Cooper, 1998), organizational commitment failed to moderate stressor-strain relationships, but in Begley and Czajka's (1993) earlier study it did moderate the relationship between two strains (i.e., initial reaction to a stressful event and subsequent consequence). A potential reason for the inconsistent results might be due to the placement of organizational commitment as a moderator of stressors and strains or a moderator of initial reaction(s) to stressors and consequences of that reaction. Studies have found organizational commitment to be a consequence of role stressors and anxiety and a predictor of withdrawal behaviors, so it makes theoretical sense to place organizational commitment as a mediator or moderator of two strains, particularly initial reaction to stressors and subsequent consequences.

\section{SIGNIFICANCE FOR ORGANIZATIONS}

Although organizations often have little control over stressors inherent to a profession or to employees' initial emotional reactions to stressors, organizations can influence employees' emotional attachment to the organization. An increase in organizational commitment might temper the extent to which anxiety would yield subsequent deviant attitudes or behaviors, including turnover intention. Viewing organizational commitment as a moderator of the relationship between initial reaction (i.e., anxiety) and turnover intention means it is a central player in reducing adverse consequences of anxiety rather than only being a consequence of it.

\section{ORGANIZATIONAL COMMITMENT}

Organizational commitment consists of three distinct components, of which two are utilized here, affective commitment and continuance commitment 
(Meyer et al., 2002). Affective organizational commitment reflects an individual's desire to remain a part of the organization, a willingness to exert effort on the part of the organization, and a belief in and acceptance of the values and goals of the organization. Continuance organizational commitment refers to one's need to stay with the organization due to limited alternatives and high sacrifice of investments one has in an organization, perhaps in terms of fringe benefits and position status. It is based on financial and status calculations one makes when deciding if he or she should remain with the organization (Reilly \& Orsak, 1991). Allen and Meyer (1990; Meyer et al., 2002) have suggested that one may have an emotional linkage to the organization but also recognize the costs of leaving without one state necessarily influencing the other. Essentially, employees rating high on affective organizational commitment (AOC) remain with the organization because they want to and those rating high on continuance organizational commitment (COC) remain because they believe they need to (Meyer, Allen, \& Gellatly, 1990; Reilly \& Orsak, 1991). Ultimately, low levels of commitment affect intentions to leave and actual severance from the organization (Meyer et al., 2002), particularly when paired with anxiety due to work.

\section{THEORETICAL REASONING: WHY ORGANIZATIONAL COMMITMENT IS A MODERATOR OF INITIAL REACTIONS AND SUBSEQUENT CONSEQUENCES}

The approaches to fitting organizational commitment into models of stress, either as an outcome or as a moderator, come from two opposing theories. The first theoretical perspective views organizational commitment as an outcome variable that results from a person's experiences with an organization (Glazer \& Beehr, 2005; O'Driscoll et al., 1992). One's relationship with the organization is a direct result of stressors and it has no adaptive function. The second perspective views organizational commitment as a moderator variable of the relationship between two stress-related variables (e.g., Begley \& Czajka, 1993; Donald \& Siu, 2001; Jamal, 1984; Leong et al., 1996; Siu, 2002).

Further, there are two potential ways in which organizational commitment can moderate the stress-strain relationship (Leong et al., 1996). First, it can intensify initial negative reactions, thereby increasing vulnerability to strain. Highly committed employees are invested in trying to resolve the organization's problems, thereby perpetuating a state of anxiety and subsequent strains. According to this perspective, commitment is a cognitive and behavioral barrier to alleviating stressors, as employees remain committed to resolving a problem. Second, it can be a coping resource (giving meaning to 
the stressful situation). This perspective, which is more consistent with mainstream thinking about organizational commitment, suggests that highly committed people, having a strong sense of security and/or belonging, will attach meaning to the stressful work situation. As pointed out by Begley and Czajka (1993), "employees committed to their company [might] be expected to benefit from the results of the tension resistance ... commitment provides" (p. 552). Accordingly, commitment is an adaptive resource that helps one make sense of the situation, thus buffering the harmful effects of stressors.

Begley and Czajka's (1993) one-item "stress" variable addressed the extent to which organizational change efforts were stressful to the respondent. Thus, their "stress" measure assessed an initial reaction to a change effort (i.e., a stressor or demanding situation) and not stressors as all the other studies have done. The outcome variable they assessed was job displeasure, a composite of job satisfaction, intent to quit, and work-related irritations. Their composite was not a clear uni-dimensional outcome variable, as others have examined and we will too. In sum, Begley and Czajka did not study commitment as a moderator of stressor-strain relationships, but the relationship between initial reaction to stressors and subsequent strains.

The distinction between studying commitment as a moderator of the stressor-strain relationship versus initial reaction and subsequent strain relationship is an important one, because often researchers incorrectly assume that the presence of a stressor is automatically equated to something noxious. A stressor only has the potential of creating negative reactions (i.e., strains); it is not a certainty that strain would develop (Beehr \& Glazer, 2005). Moreover, stressors can sometimes increase positive organizational attitudes (Beehr, Glaser, Canali, \& Wallwey, 2001). Thus, some stressors could be perceived as an exciting challenge and no strain develops. Attitudes serve to give meaning to situations (Frankl, 1984). Similarly, organizational commitment would likely serve as an adaptive, cognitive mechanism, giving direct meaning to one's association with the organization and the work one does through feelings of belonging and security (Mowday et al., 1982); that would explain, in part, when initial reaction (i.e., job-related anxiety) to stressors relates to intention to leave.

It is our contention that commitment would not buffer effects of stressors on strains, but the relationship between job stressor-induced anxiety and subsequent turnover intention. This is because when people are faced with stressors, the initial reaction is not easily controlled despite a strong commitment to the organization. Initial reactions could still be that of great anxiety. It is the subsequent consequences that require more thought before behavioral intentions are formed. Indeed, Jamal (1984) found that people with high AOC, as opposed to those who exhibit low AOC, appear to be "better off" in terms of fewer adverse reactions from role strains. Thus, high organizational commitment is likely an adaptive mechanism that 
gives meaning to the anxiety-provoking situation, alleviating subsequent deviant behaviors.

Hypothesis 1: AOC will moderate (or buffer) the relationship between job-related anxiety and intention to leave, such that the relationship will be less positive for individuals with high AOC than those with low AOC.

In addition to AOC, we examine COC. As Meyer et al. (2002) point out, even when a person is faced with other strains, one who is committed to the organization as a result of lack of alternatives and a need to stay would not leave his or her place of employment. People reporting high COC, focusing on their need to stay, are likely sensitive to the costs of leaving and, therefore, despite high anxiety they would still not leave; but with low COC and high anxiety, likelihood of leaving would increase.

Hypothesis 2: COC will moderate the relationship between job-related anxiety and intention to leave, such that the relationship will not change for people with high COC, but it will increase for those with low COC.

It is also important to rule out that commitment moderates the stressorintention to leave relationship. The premise for this study is that organizational commitment moderates the relationship between anxiety and intention to leave, but not the relationship between role stressors and intention to leave. Therefore, our final analysis tests whether the interaction between each of three role stressors and each commitment component accounts for significant variance in intention to leave.

\section{SUMMARY}

The purpose of this study on the role of organizational commitment as a moderator of the relationship between initial reaction and intention to leave is threefold. First, the intention is to replicate Begley and Czajka's (1993) findings regarding the moderating effects of AOC on the relationship between two strains, job-related anxiety and intention to leave. The second intention is to enhance the understanding of the moderating role of COC on the job-related anxiety-intention to leave relationship. No studies thus far have examined COC as a moderator of the relationship among stress-related variables, though Meyer et al.'s (2002) meta-analysis suggests that COC would work in conjunction with other attitudinal variables to explain variance in a withdrawal intention or behavior. The third goal is to find where organizational commitment belongs in occupational stress models, that is, as 
an adaptive response that can mediate or moderate first-level personal strains and consequences that might affect the organization. It is expected that (a) high AOC and (b) high COC would each individually mitigate and (c) low COC in conjunction with other affective or attitudinal outcome variables (as Meyer et al., 2002 have also found) would exacerbate negative outcomes. Furthermore, each of AOC and $\mathrm{COC}$ will not moderate the relationships between role stressors and intention to leave.

\section{METHOD}

\section{Participants}

Nurses from four hospitals in northern Israel completed a survey on occupational stress among nurses. Surveys were available to about one third of all nurses in each hospital for a total of 900 surveys administered and 506 usable questionnaires returned, yielding a response rate of 56\%. Participants ranged in age from 20 to 64 years, with a mean of 38.9 years of age $(S D=$ $9.8)$ and had been a nurse for an average of 15.1 year $(S D=9.8)$. Married nurses accounted for $78 \%$ of the sample, followed by $13 \%$ who were single. Most nurses worked full-time (62\%) and did not have higher academic degrees aside from their license as a registered nurse. All the nurses had at least Registered Nurse (RN) status, but nearly $17 \%$ had additional education, such as Bachelor of Arts and/or Master of Arts. In addition, approximately $34 \%$ held supervisory positions, such as Head of a shift, Head Nurse, Assistant Head Nurse, and Supervisor, and a majority (63\%) indicated they were regular RN staff. Nonetheless, of all the nurses, $65 \%$ supervised at least one other person. Registered nurses worked in their respective hospitals and units for an average of 10.73 years $(S D=7.76)$ and 7.98 years $(S D=6.72)$, respectively. Only $5.4 \%$ of the sample worked in the nursing profession for fewer than two years (as it was requested that nurses working for fewer than two years not participate).

\section{Measurements}

Translation. The entire survey instrument was translated and retranslated into Hebrew by three fluent Hebrew grammar teachers. The three versions were compared and discrepancies discussed between the researcher and each of the translators, as well as with a social psychology researcher. In Israel, the questionnaire was distributed among eight additional individuals, including the four Chief Nurses from the hospitals under study, who read the 
survey for content comprehension and clarity. These nurses served as subject matter experts to verify the level of complexity in completing the questionnaire and to assess the time needed to complete it.

Data collected from RNs included role stressors, job-related anxiety, AOC, COC, and intention to leave. For each of these variables, respondents answered items on a Likert-type scale with response options from 7-strongly agree through 1-strongly disagree.

Role stressors. A total of 15 items, compiled from three sources (AbdelHalim, 1978; Beehr, Walsh, \& Taber, 1976; Rizzo, House, \& Lirtzman, 1970) were used to assess each of role overload, role conflict, and role ambiguity (5 items each). Example items from each scale, respectively, are "It seems like I have too much work for one person to do," "I receive incompatible requests from two or more people," and "I know exactly what is expected of me." All role ambiguity items were reverse-coded so that a higher score indicated greater ambiguity. Alpha reliability coefficients were .81 for role overload, .63 for role conflict, and .77 for role ambiguity. The scale reliability for role conflict is low. However, in other studies using an international sample, reliabilities for this scale were acceptable (e.g., Glazer \& Beehr, 2005). Also, removing any given item would not increase reliability. Given that the assessment of role stressors is not the main point of this paper, but the study of anxiety in relation to intention to leave is, and that the survey was administered in Hebrew (in itself a potential reason for low reliability), we did not perform exploratory factor analyses to increase reliability.

Job-related anxiety. Four items adapted from Parker and DeCotiis's (1983) 15-item Job Stress Scale measured job-related anxiety. These four items best capture the notion of psycho-physiological anxiety, whereas most of the remaining items capture perceptions of high workload. Another two items that might have related to anxiety were omitted for low factor loadings and reducing reliability. The remaining four items (used also in Glazer \& Beehr, 2005) are, "I have felt fidgety or nervous as a result of my job," "My job gets to me more than it should," "There are lots of times when my job drives me right up the wall," and "Sometimes when I think about my job I get a tight feeling in my chest." A higher average score across the items is indicative of more job-related anxiety. The reliability coefficient was .74.

Continuance organizational commitment and affective organizational commitment. Affective commitment and continuance commitment were each measured through an eight-item scale developed by Allen and Meyer (1990). A higher score on this scale, after reversing six items, indicated higher AOC and COC. One COC item ("Right now, staying with my hospital is a matter of necessity as much as desire") was removed due to a low negative factor loading; retrospective content analysis indicated that the structure of the statement in Hebrew did not convey the intended meaning in English. Reliability for AOC was .81 and for COC it was .75. 
Intention to leave. A three-item measure of employees' intention to leave their jobs was adapted from the Michigan Organizational Assessment Questionnaire (Seashore, Lawler, Mirvis, \& Cammann, 1982). One item was modified from the form of a question to a statement (i.e., "I will actively look for a new job in the next year") that follows the item structure of the other two items (i.e., "I often think about quitting" and "I will probably look for a new job in the next year"). A high composite score indicated an intention to leave the employing organization. Coefficient alpha for intention to leave was .81 .

\section{Procedure}

Nine hundred structured questionnaires were distributed among onethird the number of Registered Nurses from most inpatient units in each of four hospitals in northern Israel in summer 1994. Three of the four hospitals were public government-run hospitals and one was associated with a specific insurance company. The specific hospitals were selected because they are located in the same region of Israel; proximity to each other was essential in providing the first author with the ability to maintain close contact with the nurses in a limited time frame. In one hospital (with 90 respondents), up to 150 nurses (about 1/3 of the hospital nursing population) could voluntarily complete the survey. These nurses were instructed to return the completed questionnaire to the Chief Nurse's office (no envelope was provided) in a sealed box with a small opening to insert the survey. In two other hospitals (in which 49 out of 150 surveys in one and 113 out of 175 surveys in the other were completed), surveys were delivered directly to randomly selected nurses (by randomly choosing a number and then counting every third nurse on a bulletin board list of all nurses); they were instructed to seal their completed survey in a preaddressed envelope and send them through internal mail to the Chief Nurse's office. In the fourth hospital (with 254 out of 425 surveys completed), head nurses in each unit were given approximately one third the number of surveys as there were nurses in the unit (because some units had as few as three nurses, all nurses received the survey) and asked to distribute the surveys to nurses in each of the shifts. Envelopes were provided with the survey and nurses could seal their completed survey and then place it into a larger envelope that was addressed to the Research Unit and returned through internal mail. Nurses were given approximately two weeks to complete and return the questionnaires. 


\section{Data Analyses}

Each of the four hospitals was different in size (i.e., number of beds) and population served. However, only location and hospital-type had any clear relationship with mean scores on the main study variables. Intention to leave was greater for nurses in the insurance-run hospital than for nurses in the hospital located in a different city (lowest level of intention to leave) and for nurses in the largest hospital of the three in the northern city. Continuance commitment was greater among nurses in the hospital located in a different city than the smallest of the three hospitals located in the northern city. This is likely due to the fact that this was the only hospital from that city. Thus, for subsequent analyses, dummy-coded hospital was controlled (per Cohen \& Cohen's, 1983, instruction for nominal variables).

\section{RESULTS}

Descriptive statistics consisting of means, standard deviations, and correlations (based on centered variables) among study variables are reported in Table 1. Based on previous research, correlations are consistent with our expectations.

Moderated regression analyses were performed for each of the commitment components and job-related anxiety on intention to leave, as well as each of the commitment components with each of the role stressors on both job-related anxiety and intention to leave, in the manner suggested by Cohen and Cohen (1983) and Baron and Kenny (1986). In each regression equation, the predictor variable was entered first in the regression equation, followed by either AOC or COC, and finally the interaction between the commitment component and the predictor variable, computed as the product of (affective or continuance) commitment $\times$ predictor variable. All the variables were centered prior to performing analyses (Aiken \& West, 1991).

Two conservative hierarchical regression analyses were performed. First, intention to leave was regressed on (dummy-coded) hospitals, if one supervised others, age, tenure in hospital, and employment status (step 1), jobrelated anxiety (step 2), AOC and COC (step 3), and the interaction between job-related anxiety and both AOC and COC (see Table 2). Second, intention to leave was regressed on hospitals, age, tenure in hospital, and employment status (step 1), role stressors (step 2), AOC and COC (step 3), and the interaction between each role stressor and commitment component (step 4).

Table 2 shows that dummy-coded hospitals, supervisory role, age, tenure, and employment status (full-time or part-time) account for a significant 9\% of variance in intention to leave and that job-related anxiety and both 


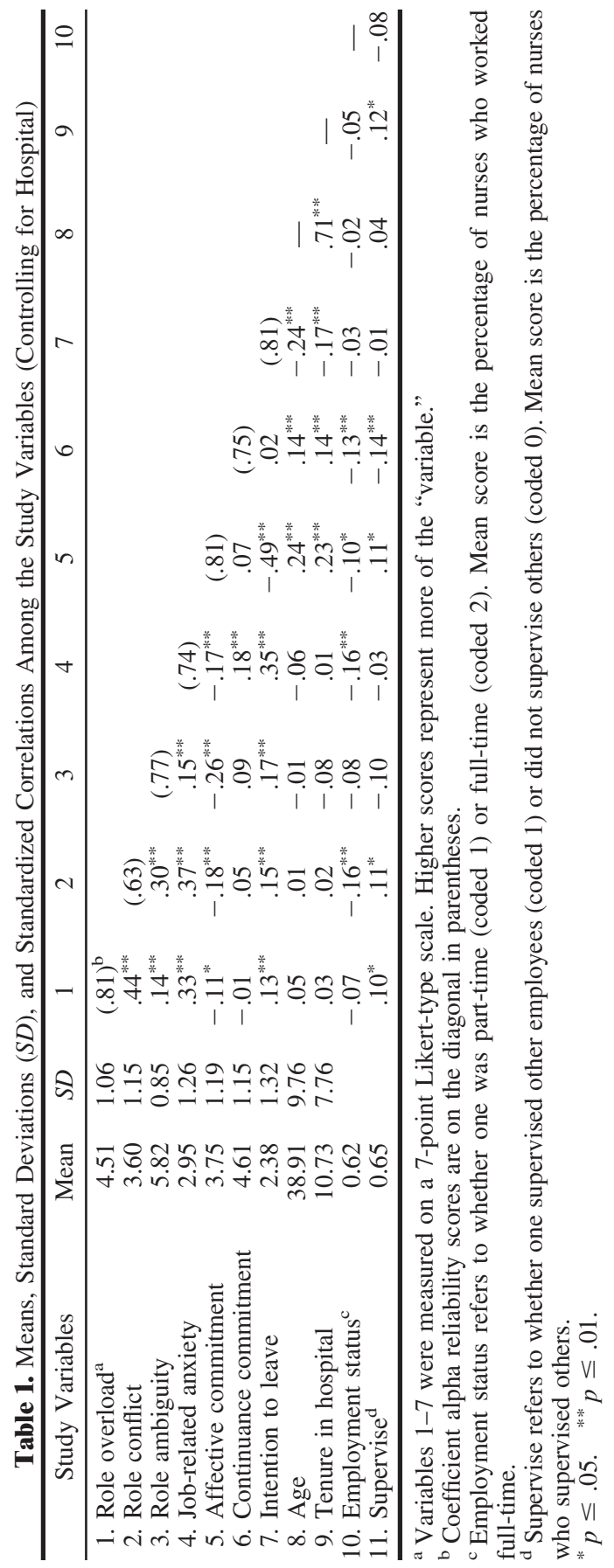


Table 2. Intention to Leave Regressed on Job-Related Anxiety, Affective Commitment, Continuance Commitment, and the Interaction Between Job-Related Anxiety and Both Affective and Continuance Commitment

\begin{tabular}{|c|c|c|}
\hline Variables & $\beta$ & $\Delta \mathrm{R}^{2}$ \\
\hline Step 1: Dummy hospital 1 & $-.21^{* *}$ & $.09^{* * *}$ \\
\hline Dummy hospital 2 & -.08 & \\
\hline Dummy hospital 3 & $-.22^{* *}$ & \\
\hline Supervise others & .04 & \\
\hline Age & $-.16^{* *}$ & \\
\hline Tenure & .05 & \\
\hline Employment status & -.04 & \\
\hline Step 2: Job-related anxiety (a) & $.25^{* *}$ & $.10^{* * *}$ \\
\hline Step 3: Affective commitment (b) & $-.43^{* *}$ & $.17^{* * *}$ \\
\hline Continuance commitment (c) & .01 & \\
\hline Step 4: $\mathrm{a} \times \mathrm{b}$ & $-.08^{*}$ & $.02^{* * *}$ \\
\hline$a \times c$ & $-.12^{*}$ & \\
\hline
\end{tabular}

Note. Variables were centered prior to performing analyses. The standardized regression coefficients are those obtained at Step 4 .

${ }^{*} p \leq .05 .{ }^{* *} p \leq .01$.

AOC and COC account for an additional significant $27 \%$ of variance in intention to leave. An additional $2 \%$ of variance is accounted for in intention to leave by the interaction terms of job-related anxiety with each of AOC and COC. Consistent with hypothesis 1 , the interaction between AOC and jobrelated anxiety is significant $(\beta=-.08, p<.05)$. Figure 1 shows that the relationship between job-related anxiety and intention to leave is more positive for nurses with low AOC than nurses with high AOC. High AOC buffers the relationship between job-related anxiety and turnover intention.

Table 2 shows that COC does not account for significant variance in intention to leave in the fourth step, but the interaction term between job-related anxiety and COC is significant $(\beta=-.12, p<.05)$. Consistent with hypothesis 2 , when $\mathrm{COC}$ is low, the relationship between anxiety and turnover intention is more positive than when COC is high (see Figure 2). It also appears that high COC buffers the relationship between job-related anxiety and intention to leave. Specifically, when COC is high, the relationship between anxiety and intention to leave is less positive than when COC is low.

Because one purpose of this paper was to demonstrate that commitment is best suited as a moderator between two strains than between stressors and strains, moderated regression analysis was employed again, but with role stressors as the predictor variables. Results indicate that although role stressors and organizational commitment together accounted for an additional $21 \%$ of variance in intention to leave (after control variables), none of the role stressors' standardized coefficients were significant in the fourth step. Moreover, together the six interaction terms accounted for an additional nonsignificant $1 \%$ of variance in intention to leave. Of the six interaction terms, only that of COC and role conflict yielded a significant beta weight 


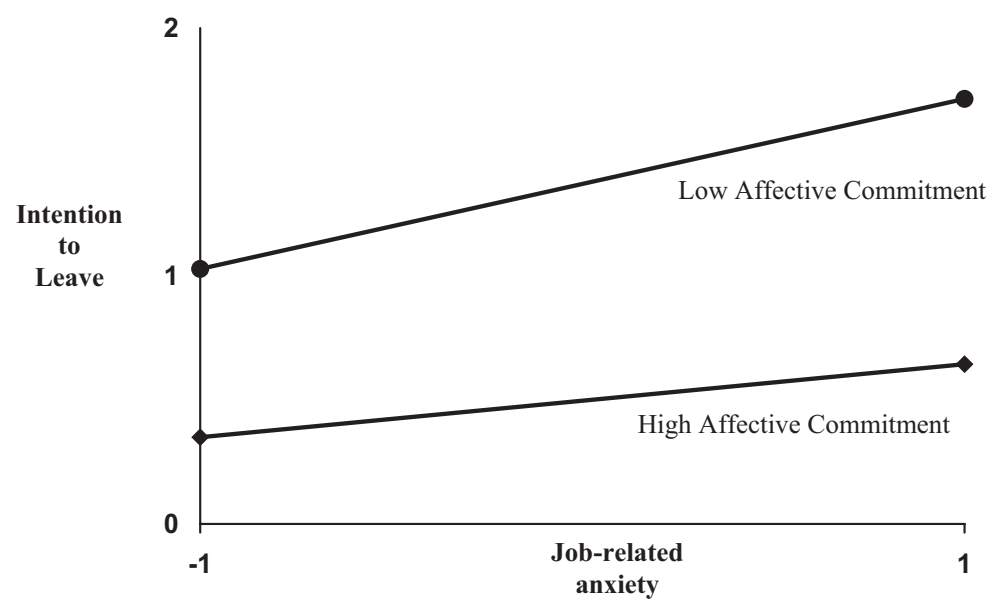

Low AOC: $\mathrm{Y}=1.37+0.34$ (Anxiety)

High AOC: $\mathrm{Y}=0.50+0.15$ (Anxiety)

Figure 1. Interaction between job-related anxiety and affective commitment on intention to leave.

( $\beta=-.09, p=.04)$. However, in order to control for Type I error, one would divide the probability value by the number of interaction terms and determine that the interaction term was not significant and there is little support for organizational commitment as a moderator of stressor-intention to leave relationships (reader may request a copy of the regression table from first author).

Although not theoretically driven, a post hoc analysis showed that job-related anxiety regressed on control variables (step 1), three role stressors (step 2), two organizational commitment components (step 3), and the six interaction terms (step 4) also did not yield a significant change in variance in the fourth step.

\section{DISCUSSION}

This study explored and found support for our contention that organizational commitment is a moderator of the relationship between jobrelated anxiety and intention to leave and not the relationship between role stressors and intention to leave. Below, we discuss findings and support for the placement of organizational commitment as a moderator of two strains. 


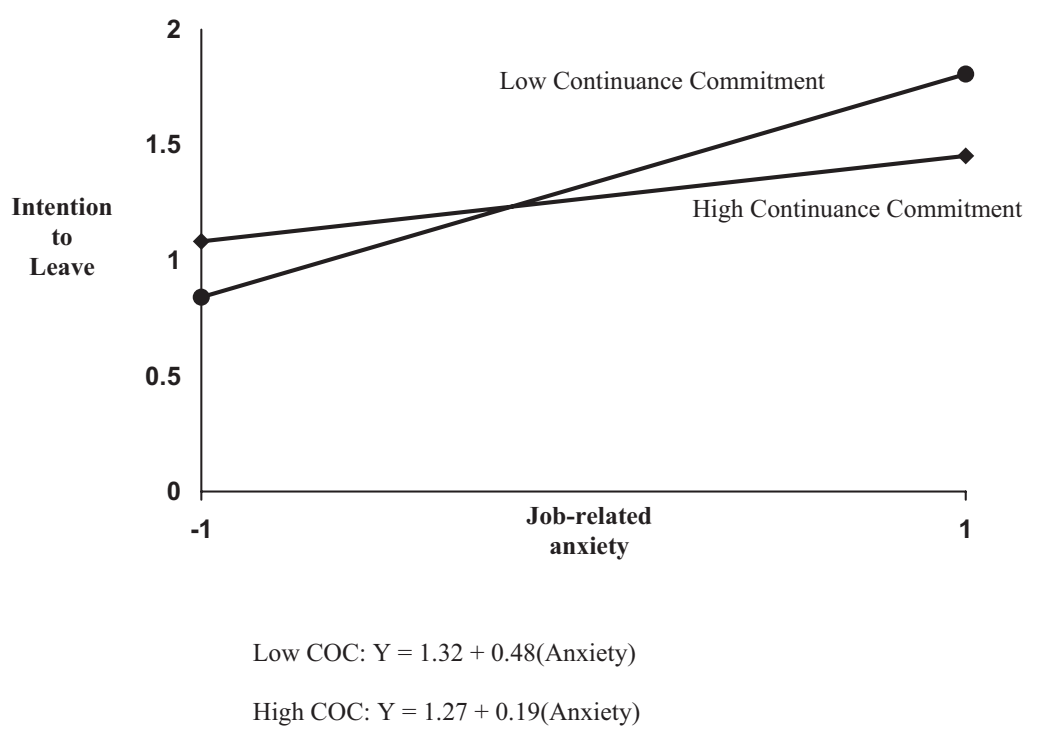

Figure 2. Interaction between job-related anxiety and continuance commitment on intention to leave.

The mean scores reported in Table 1 for each of the main study variables indicate that role stressors are fairly high (greater than 3.5 on a 1 to 7 scale) and both job-related anxiety level and intention to leave are fairly low for this group of nurses (less than 3.0 on a 1 to 7 scale). Given the nature of a nurse's job, it is not surprising that they would report high levels of role overload, but high levels of role ambiguity were unexpected. Second, it is unusual that the level of job-related anxiety is not greater across the group. Third, that COC and intention to leave did not correlate (as suggested by Mathieu \& Zajac, 1990) is not entirely unexpected, given that a recent cross-cultural study of stress among nurses only found a significant correlation between these two variables in one of the four countries (i.e., in Hungary, but not Italy, U.K., or U.S.A.; Glazer \& Beehr, 2005) and Meyer et al.'s (2002) meta-analysis demonstrated that COC and intention to leave were either not correlated or they correlated negatively.

Nonetheless, results of this study support the hypotheses and provide further support for Begley and Czajka's (1993) report that commitment moderates the relationship between initial reaction to stressors (i.e., anxiety) and intention to leave, but not between role stressors and intention to leave. Both COC and AOC moderate the relationship between job-related anxiety and intention to leave in the predicted directions. Generally, high AOC and high COC each mitigate the relationship between job-related anxiety and intention to leave, whereas high job-related anxiety yields greater intention to 
leave when $\mathrm{COC}$ is low. The relationship between job-related anxiety and intention to leave has only a slight positive slope for those with high COC. This is likely resulting from a need to stay due to lack of alternatives or perceived high sacrifice. As Meyer et al. (2002) note, "employees with high continuance commitment should intend to remain with their employer to avoid costs associated with leaving" (p. 39). They further explain that counterproductive behaviors or attitudes that could be associated with low COC only become evident when other factors are also bleak (e.g., high job-related anxiety or low AOC).

The moderating effects of organizational commitment on the relationship between two strains have not been investigated extensively, though commitment is considered an important topic to study by most researchers because of its implications on absenteeism and turnover. This study is just one that empirically supports the contention that AOC and COC moderate the relationship between initial reaction to stressors and intention to leave. Thus, organizational commitment is likely an adaptive, cognitive mechanism that helps alleviate intention to leave due to anxiety. Commitment appears to provide meaning to one's overall relationship with the organization. Due to its rather stable and global nature, when organizational commitment is high, one might better accept the anxiety produced from stressors and develop fewer subsequent consequences. In contrast, when organizational commitment is low, having anxiety justifies one's intentions to leave the workplace. That commitment does not moderate the stressor-strain relationship might be due to the fact that not all stressors lead to strains.

Results of this study have implications for hospitals. Turnover is a salient problem for hospitals and research like this provides a better understanding of the nature of this problem. Needing to stay with an organization because alternatives are not available is probably not a healthy attitude to hold toward an organization, but it might still help one cope with anxiety (by virtue of knowing one must stay despite anxiety from stressors). The present study shows that as job-related anxiety increases, intention to leave is not as likely for nurses with high COC, but intention to leave increases for nurses with low COC. This suggests that as soon as more opportunities open, nurses might leave the organization. This further raises the question: what might be improved in these hospitals so that nurses who are reporting high COC will eventually feel that they are staying despite the availability of alternatives and despite other opportunities. In other words, what can these organizations do to create a sense of affiliation with the hospital and not a sense of contractual relations?

Apropos, individuals with high AOC (vs. low on AOC) and low jobrelated anxiety report lower turnover intention. This implies that hospitals in Israel should pay close attention to creating an environment in which nurses want to be with the hospital. Whether or not nurses are anxious, emotional 
attachment to the hospital helps reduce intentions to leave. Nurses that sense an emotional attachment, while also feeling anxious, indicate moderate intention to leave.

\section{Limitations}

The greatest limitations to the present study are common method variance and the cross-sectional design. Other ways of assessing anxiety include actual physiological measures (e.g., salivary cortisol and blood pressure). In addition, collecting data on actual turnover or absenteeism (frequency and duration) could help solidify the proposal that high organizational commitment buffers the effects of anxiety on withdrawal behaviors. Nonetheless, these ideas notwithstanding, concern over common method variance is minimal given that significant interaction effects were found (Aiken \& West, 1991).

\section{REFERENCES}

Abdel-Halim, A. A. (1978). Employee affective responses to organizational stress: Moderating effects of job characteristics. Personnel Psychology, 31, 561-579.

Aiken, L. S., \& West. S. G. (1991). Multiple regression: Testing and interpreting interactions. Newbury Park. CA: Sage.

Allen, N., \& Meyer, J. (1990). The measurement and antecedents of affective, continuance, and normative commitment. Journal of Occupational Psychology, 63, 1-18.

Bakker, A. B., Demerouti, E., de Boer, E., \& Schaufeli, W. B. (2003). Job demands and job resources as predictors of absence duration and frequency. Journal of Vocational Behavior, 62, 341-356.

Baron, R. M., \& Kenny, D. A. (1986). The moderator-mediator variable distinction in social psychological research: Conceptual, strategic, and statistical considerations. Journal of Personality and Social Psychology, 51, 1173-1182.

Beehr, T. A., Glaser, K. M., Canali, K. G., \& Wallwey, D. A. (2001). Back to basics: Re-examination of demand control theory of occupational stress. Work \& Stress, 15, $115-130$.

Beehr, T. A., \& Glazer, S. (2005). Organizational role stress. In J. Barling, K. Kelloway, \& M. Frone (Eds.), Handbook of Work Stress (pp. 7-33). Thousand Oaks, CA: Sage.

Beehr, T. A., Walsh, J. T., \& Taber, T D.. (1976). Relationship of stress to individually and organizationally valued states: Higher order needs as a moderator. Journal of Applied Psychology, 61, 41-47.

Begley, T., \& Czajka, J. (1993). Panel analysis of the moderating effects of commitment on job satisfaction, intent to quit, and health following organizational change. Journal of Applied Psychology, 78, 552-556.

Cohen, J., \& Cohen, P. (1983). Applied multiple regression/correlation analysis for the behavioral sciences (2nd ed.). London: Erlbaum.

Donald, I., \& Siu, O. (2001). Moderating the stress impact of environmental conditions: The 
effect of organizational commitment in Hong Kong and China. Journal of Environmental Psychology, 21, 353-368.

Frankl, V. E. (1984). Man's search for meaning: An introduction to logotherapy. New York: Houghton Mifflin.

Glazer, S., \& Beehr, T. A. (2005). Consistency of the implications of three role stressors across four countries. Journal of Organizational Behavior, 26, 467-487.

Jamal, M. (1984). Job stress and job performance controversy: An empirical assessment. Organizational Behavior and Human Performance, 33, 1-21.

Leiter, M. (1988). Commitment as a function of stress reactions among nurses: A model of psychological evaluations of work settings. Canadian Journal of Community Mental Health, 7, 117-133.

Leong, C. S., Furnham, A., \& Cooper, C. L. (1996). The moderating effect of organizational commitment on the occupational stress outcome relationship. Human Relations, 49, $1345-1363$

Mathieu, J., \& Zajac, D. (1990). A review and meta-analysis of the antecedents, correlates, and consequences of organizational commitment. Psychological Bulletin, 108, 171-194.

Meyer, J. P., Allen, N. J., \& Gellatly, I. R. (1990). Affective and continuance commitment to the organization: Evaluation of measures and analysis of concurrent and time-lagged relations. Journal of Applied Psychology, 75, 710-720.

Meyer, J. P., Stanley, D. J., Herscovitch, L., \& Topolnytsky, L. (2002). Affective, continuance, and normative commitment to the organization: A meta-analysis of antecedents, correlates, and consequences. Journal of Vocational Behavior, 61, 20-52.

Mowday, R., Porter, L., \& Steers, R. (1982). Employee-organization linkages: The psychology of commitment, absenteeism, and turnover. New York: Academic Press.

O’Driscoll, M., Ilgen, D., \& Hildreth, K. (1992). Time devoted to job and off-job activities, interrole conflict, and affective experiences. Journal of Applied Psychology, 77, 272-279.

Parker, D. F., \& DeCotiis, T. A. (1983). Organizational determinants of job stress. Organizational Behavior and Human Performance, 32, 160-177.

Reilly, N. P. (1994). Exploring a paradox: Commitment as a moderator of the stressor-burnout relationship. Journal of Applied Social Psychology, 24, 397-414.

Reilly, N. P., Dwight, S. A., Godfrey, K. J., Davis, P. A., \& Lynch, R. S. (1994). Career commitment buffers the stress. Applied HRM Research, 5, 12-27.

Reilly, N. P., \& Orsak, C. L. (1991). A career stage analysis of career and organizational commitment in nursing. Journal of Vocational Behavior, 39, 311-330.

Rizzo, J. R., House, R. J., \& Lirtzman, S. I. (1970). Role conflict and ambiguity in complex organizations. Administrative Science Quarterly, 15, 150-163.

Seashore, S. E., Lawler, E. E., Mirvis, P., \& Cammann, C. (Eds.). (1982). Observing and measuring organizational change: A guide to field practice. New York: Wiley.

Siu, O. (2002). Occupational stressors and well-being among Chinese employees: The role of organisational commitment. Applied Psychology: An International Review, 51, 527-544.

Siu, O. L., \& Cooper, C. L. (1998). A study of occupational stress, job satisfaction, and quitting intention in Hong Kong firms: The role of locus of control and organizational commitment. Stress Medicine, 14, 55-66. 